\title{
A EXTENSÃO COMO COLABORAÇÃO PARA O SERTÃO: VIVÊNCIAS DO IFRN NO SERIDÓ POTIGUAR
}

\author{
Danilo Cortez Gomes \\ danilo.cortez@ifrn.edu.br \\ Instituto Federal de Educação, Ciência e Tecnologia do Rio Grande do Norte \\ DOI: $10.15628 /$ rbept.2018.6858
}

Artigo submetido em jan/2018 e aceito em mar/2018

\begin{abstract}
RESUMO
Atualmente, no Brasil, a educação profissional e tecnológica por meio dos Institutos Federais de Educação, Ciência e Tecnologia tem sido um valioso instrumento para milhares de comunidades que podem ter acesso a um ensino de qualidade, bem como das outras vertentes institucionais como a pesquisa e principalmente a extensão, que proporciona maior visibilidade a instituição e ao mesmo tempo consegue ir ao encontro das necessidades reais e urgentes das comunidades (PACHECO, 2011). Vale salientar que a expansão desses institutos tem possibilitado mudanças de "paisagens" sociais, tendo em vista os 644 campi em funcionamento, distribuídos em 568 municípios espalhados em todos os estados brasileiros (BRASIL, 2016), dentre eles o Rio Grande do Norte e mais especificamente, a região do Seridó potiguar. Desse modo, esse trabalho buscou apresentar as ações e resultados de dois projetos de extensão promovidos pelo IFRN - Campus Currais Novos que foram voltados para a agroecologia e apicultura, abordando as duas faces da extensão: a da comunidade como beneficiária das ações; e a dos discentes e docentes enquanto prática pedagógica que auxilia na formação humana integral da educação profissional e tecnológica. A pesquisa é baseada no paradigma interpretativo e tem natureza qualitativa com caráter descritivo, tendo sido realizada por meio de pesquisa documental e observação participante. Os resultados reforçam que uma das finalidades dos Institutos Federais é atuar em favor do desenvolvimento local, observando as peculiaridades e principais necessidades da região.
\end{abstract}

PALAVRAS-CHAVE: Extensão, educação profissional, IFRN, Seridó.

\section{THE EXTENSION AS COLLABORATION FOR THE SERTÃO: IFRN'S LIVES IN THE SERIDÓ POTIGUAR}

\begin{abstract}
Currently, in Brazil, the professional and technological education through the Federal Institutes of Education, Science and Technology, had been a valuable instrument for thousands of communities that can have access to quality education, as well as other institutional aspects such as research and mainly the extension that provides greater visibility and a same goal for meeting the real and urgent needs of communities (PACHECO, 2011). It is worth noting that the expansion of the institutes has made possible changes of socials "landscapes", in view of 644 campus in activity, distributed in 568 cities in all Brazilian states (BRAZIL, 2016), among them Rio Grande do Norte and more specifically, the region of Seridó potiguar. In this way, this work sought to show the actions and results of extension projects promoted by the IFRN - Campus Currais Novos that were focused on agroecology and apiculture, addressing as two faces of extension: that of the community as beneficiary of the actions; and that of students and teachers as a pedagogical practice that assists in the integral human formation of professional and technological education. The research is based on the interpretative paradigm and has a qualitative nature with a descriptive character, having been realized by means of documentary research and participant observation. The results reinforce that one of the aims of the Federal Institutes is act in favor of local development, observing the peculiarities and main needs of the region.
\end{abstract}

KEYWORDS: Extension, professional education, IFRN, Seridó. 


\section{INTRODUÇÃO}

Nos últimos anos e mais especificamente nas quase duas primeiras décadas deste século, a educação profissional e tecnológica no Brasil, tem tomado proporções substanciais no que se refere à expansão e interiorização, principalmente por meio dos Institutos Federais, através de investimentos governamentais na tentativa de proporcionar aos cidadãos uma educação técnica e profissional nos diversos rincões do país, com o intuito de fomentar e preencher lacunas existentes na sociedade, tais como a falta de qualificação e apoio institucional para o desenvolvimento local e regional dos arranjos produtivos locais, além de tentar promover por meio do ensino, da pesquisa e da extensão, o desenvolvimento local e regional nas localidades e regiões em que essas instituições estão inseridas. Uma das formas mais atuantes da educação profissional e tecnológica junto a sociedade se dá por meio das atividades de extensão.

A Lei 11.892/2008 que institui a Rede Federal de Educação Profissional, Científica e Tecnológica, criando os Institutos Federais de Educação, Ciência e Tecnologia, deixa bem claro que duas das suas finalidades e características são orientar sua oferta formativa em benefício da consolidação e fortalecimento dos arranjos produtivos, sociais e culturais locais, identificados com base no mapeamento das potencialidades de desenvolvimento socioeconômico e cultural; e desenvolver programas de extensão e de divulgação científica e tecnológica (Art. 6o, Incisos IV e VII), tendo dentre seus objetivos, o desenvolvimento de atividades de extensão de acordo com os princípios e finalidades da educação profissional e tecnológica, em articulação com o mundo do trabalho e os segmentos sociais, e com ênfase na produção, desenvolvimento e difusão de conhecimentos científicos e tecnológicos, e o estímulo e apoio a processos educativos que levem à geração de trabalho e renda e à emancipação do cidadão na perspectiva do desenvolvimento socioeconômico local e regional (Art. 7ํㅡ, Incisos IV e V).

Nesse cenário, a expansão e interiorização da Rede Federal de Educação Profissional e Tecnológica (RFEPT) através dos diversos campi espalhados nas mais distintas regiões do Brasil, torna-se "posição estratégica importante como elemento criativo de alavancagem, junto com outras políticas e ações públicas, para o desenvolvimento socioeconômico do Brasil" (BRASIL, 2004 , p. 6). Ressalta-se a elevação dos números relacionados à temática em questão, a saber: de 1909 a 2002 foram construídas 140 escolas técnicas no país, e de 2003 a 2016 já foram disponibilizadas mais de 500 novas unidades. Com investimentos consideráveis no projeto de expansão, atualmente a RFEPT consta com 644 campi em funcionamento, sendo distribuídos em 568 municípios espalhados em todos os estados brasileiros (BRASIL, 2016).

Desta maneira, sendo a educação profissional e tecnológica uma temática pertinente, e observando o aspecto da extensão enquanto política de interação com a sociedade, esse estudo buscou apresentar as ações e resultados de dois projetos de extensão promovidos pelo IFRN Campus Currais Novos voltados para a agroecologia e apicultura, dando ênfase ao que chamamos das duas faces da extensão, isto é, a da comunidade como beneficiária das ações; e a dos discentes e docentes enquanto prática pedagógica que auxilia na formação humana integral da educação profissional e tecnológica. É nessa perspectiva que Pacheco (2015, pp. 89) afirma: 


\begin{abstract}
Ora, se o papel dos Institutos Federais está visceralmente vinculado ao desenvolvimento local e à promoção da cidadania, as atividades de extensão (inciso IV) tornam-se essenciais para o diálogo efetivo entre instituição e sociedade. (...) As atividades de extensão são também valiosos instrumentos para inserção do egresso no mundo do trabalho e a manutenção de seu vínculo com a instituição, como canal de informações sobre a efetividade das ações institucionais diante do cumprimento de suas finalidades.
\end{abstract}

\title{
2 REVISÃO BIBLIOGRÁFICA
}

\subsection{A extensão como colaboração nos Institutos Federais}

Na gênese dos Institutos Federais por meio da Lei 11.892/2008, a importância da extensão enquanto política de interação com a sociedade já fora enfatizada, apresentando a indissociabilidade entre o ensino, a pesquisa e extensão, sendo esta última, um dos componentes principais para atuar junto às potencialidades locais e regionais, isto é, almejando o desenvolvimento socioeconômico das regiões nas quais a educação profissional e tecnológica está diretamente inserida. Por isso, a referida lei traz como um dos objetivos dessas instituições:

\footnotetext{
desenvolver atividades de extensão de acordo com os princípios e finalidades da educação profissional e tecnológica, em articulação com o mundo do trabalho e os segmentos sociais, e com ênfase na produção, desenvolvimento e difusão de conhecimentos científicos e tecnológicos. (BRASIL, 2008, Art. 7o, Inciso IV)
}

Mas quais os princípios e finalidades da educação profissional e tecnológica? De que modo ocorrerão essas articulações com o mundo do trabalho e os segmentos sociais? De maneira muito clara, o Projeto Político Pedagógico do IFRN (2012) traz as respostas a esses questionamentos ao elencar as características e finalidades básicas da instituição quando relacionada à extensão, tais como: a orientação da oferta formativa em benefício da consolidação, do desenvolvimento e do fortalecimento dos arranjos produtivos sociais e culturais, identificados com base no mapeamento das potencialidades locais e regionais; o desenvolvimento de programas de extensão e de divulgação científica e tecnológica; e a promoção da produção, o desenvolvimento e a transferência de tecnologias, notadamente as voltadas à sustentabilidade ambiental e às demandas da sociedade. (IFRN, 2012). Essas características são imprescindíveis para que a função social da instituição seja realizada a contento, ou seja, os beneficiários da educação profissional e tecnológica não são apenas os discentes, mas toda a comunidade que atua, colabora, integra direta ou indiretamente a 
instituição, pois "o processo de interação com a sociedade implementado no IFRN defende a perspectiva de articular mecanismos de extensão às ações de ensino e de pesquisa, numa relação de verticalização do ensino e, ao mesmo tempo, numa relação horizontal com as comunidades interna e externa (IFRN, 2012, p. 199). Observando atentamente as finalidades da educação profissional e tecnológica, percebe-se nitidamente a insistência no estabelecimento de uma relação transformadora com a sociedade, fazendo com que as ações de extensão surjam como o elo entre as demandas sociais, o ensino e a pesquisa, buscando impactar na contínua revisão e harmonização do ensino e da pesquisa com as necessidades socioeconômicas e culturais locais. Obviamente que essa comunicação constante, semelhante aquela proposta por Freire (2015) se dá por meio de um diálogo permanente com os conhecimentos produzidos pela sociedade (PACHECO, 2011). Na verdade, a função social vai muito além da oferta de um ensino de qualidade:

O compromisso da Instituição é cumprir sua função social, promovendo mudanças significativas no âmbito da formação humana, da formação para o trabalho e do desenvolvimento social e econômico. Persegue-se, assim, uma atuação integrada e referenciada - local, regional e nacionalmente - possibilitando o entrelaçamento entre desenvolvimento, territorialidade e educação sistêmica (IFRN, 2012, p. 35).

É justamente esse desafio de um novo fazer pedagógico que torna a expansão e interiorização da educação profissional e tecnológica um grande desafio e ao mesmo tempo, uma esperança para tantos brasileiros que além de um ensino de qualidade, buscam o auxílio de subsídios que possam melhorar suas vidas. Dito isto, entende-se que as ações dos Institutos Federais devem estar intimamente vinculadas às realidades locais e regionais, isto é, essa interação e comunicação precisam ser constantes e permanentes, como defende Pacheco (2011, p. 27):

o fazer pedagógico desses institutos, ao trabalhar na superação da separação ciência/tecnologia e teoria/prática, na pesquisa como princípio educativo e científico, nas ações de extensão como forma de diálogo permanente com a sociedade, revela sua decisão de romper com um formato consagrado, por séculos, de lidar com o conhecimento de forma fragmentada.

Nessa linha de raciocínio, a educação profissional e tecnológica "assume o currículo como um conjunto integrado e articulado de atividades intencionadas, pedagogicamente concebidas a partir da visão crítica de ser humano, de mundo, de sociedade, de trabalho, de cultura e de educação, organizadas para promover a construção, a reconstrução, a socialização e a difusão do 
conhecimento" (IFRN, 2012, p. 55), perseguindo uma formação integral para os alunos, que além do conhecimento técnico e específico, os habilita para torná-los cidadãos que possam contribuir com o desenvolvimento socioeconômico local, regional, nacional e global, na perspectiva da edificação de uma sociedade democrática e solidária. (IFRN, 2012).

Nesse sentido, as ações de extensão, como as que são objetos de estudo deste trabalho, possibilitam que as compreensões dos alunos sejam além da aparência, ou seja, é dada a oportunidade de conhecerem a realidade, as nuances do cotidiano, os desafios enfrentados por homens e mulheres comuns que lidam com inúmeras dificuldades para manterem seus negócios, suas dignidades. Desse modo, os futuros profissionais que passam a ter um entendimento mais nítido da realidade concreta que se dá por múltiplas e infindáveis relações entre os sujeitos. Todavia, nem sempre o conteúdo específico da "sala de aula" permite um horizonte tão amplo, fazendo-se necessário ir além dos muros das instituições escolares, sejam os alunos, sejam os educadores como promotores e incentivadores dessas descobertas. Assim, a extensão unida às formações acadêmicas e profissionais, se torna colaboração em todos os sentidos. Colaboração que vai além dos muros institucionais e busca comunicar-se com o mundo externo, e este, com o interno. Ocorre nesse momento um intenso movimento e troca de saberes diversos, expandindo e prolongando, significados próprios da palavra extensão, uma convivência salutar que deve e precisa ocorrer em prol do desenvolvimento local e regional, bem como da formação integral do aluno:

\footnotetext{
Para o fortalecimento e a consolidação dessas atividades extensionistas, é importante estimular os educadores a conhecerem a realidade das regiões onde os campi estão inseridos, identificando problemas e potencialidades. Desenvolvidos com a participação dos servidores (docentes e técnico-administrativos), estudantes e a comunidade externa, os projetos de extensão, implementados na perspectiva de atuação conjunta com o ensino e a pesquisa, resultam em efetiva intervenção na realidade. Saberes diversos são difundidos, aprofundados e inovados (IFRN, 2012, pp. 200-201).
}

O tripé ensino, pesquisa e extensão precisam estar bem alinhadas na instituição ao passo que cada campus em determinada localidade deve explorar as potencialidades territoriais, inserindo-se na dinamicidade própria dessas regiões. Segundo Pacheco (2015, p. 33), "a pesquisa só tem sentido quando se transforma em extensão, pois ela, necessariamente, tem de ser aplicada, útil à sociedade ou não servirá para nada". Para o autor, a produção de tecnologias sociais deve ser uma das prioridades dos Institutos Federais (PACHECO, 2015).

\subsection{As formações acadêmicas e profissionais por meio dos projetos de extensão}

Atualmente, percebe-se um crescimento considerável de consumidores que demandam produtos orgânicos ou que estejam de acordo com as boas práticas agrícolas, todavia, um dos 
principais desafios num país de proporções geográficas continentais como o Brasil é, além da oferta desses produtos, criar um mercado propício e desenvolvido que possua uma gestão agrícola empreendedora e se adéqüe as necessidades desse mercado que tende a crescer, segundo Sediyama, Santos e Lima (2014, p. 836):

\begin{abstract}
a preocupação do consumidor brasileiro com a qualidade nutricional e a inocuidade dos alimentos que consome tem aumentado. Em muitos artigos científicos e em manchetes de jornais, observam-se relatos de contaminação de alimentos, em especial de hortaliças, com agrotóxicos, fato que tem despertado o interesse do consumidor por produtos orgânicos, que têm sido considerados mais confiáveis com relação a essa problemática.
\end{abstract}

De acordo com Penteado (2007), o sistema agroecológico exclui o uso de agrotóxicos e fertilizantes sintéticos que são agressivos e prejudiciais à saúde e ao meio ambiente, procurando uma interação entre as necessidades do agricultor enquanto produtor (oferta) e as necessidades do consumidor (demanda), em prol de satisfazer as partes envolvidas nesse "acordo" que deve ser fomentado pela corresponsabilidade entre ambos.

As Boas Práticas Agrícolas (BPA) ou Good Agricultural Practices (GAP), em inglês, se constituem em um programa que contempla um conjunto de procedimentos adotados no campo que visa proporcionar a segurança da matéria-prima produzida. Tendo por base o Manual de Boas Práticas Agrícolas para a Agricultura Familiar, as Boas Práticas Agrícolas definem-se como "cultivar os produtos da melhor forma e por sua vez dar garantia dos mesmos". Assim, as BPA's são um conjunto de princípios, normas e recomendações técnicas aplicadas para a produção, processamento e transporte de alimentos, orientadas essencialmente de forma a salvaguardar a saúde humana, proteger o meio ambiente e melhorar as condições de trabalho dos produtores. De todo modo, uma das vantagens desse tipo de produção está na menor utilização de fitofármacos (menos custos) e consequentemente em maiores rendimentos ou aumento da produtividade.

Segundo Bastos (2008), as boas práticas agrícolas devem ser estabelecidas tomando como base os riscos associados com os produtos, sejam eles de origem animal ou vegetal, e ainda utilizar os dados disponíveis na literatura que tenham respostas científicas aos perigos que possam ser encontrados no campo. Por isso, essas práticas têm sido constantemente discutidas pelo comitê de higiene de Codex Alimentarius, sendo os documentos "Proposed draft code of hygienic practice for the primary production, harvest in gandpackaging of fresh fruits and vegetables" e "Proposed draft ode of hygienic practice for pre-cut fruits and vegetables", os norteadores dessas discussões (CODEX, 2000).

Para se ter uma visão mais ampla do assunto, Neves (2007) enfatiza que as boas práticas agrícolas estabelecem requisitos para as operações agropecuárias com foco na produção seguro de alimentos, que envolve desde o manejo do solo e água, a utilização do esterco e fertilizantes, a produção vegetal e animal, o manuseio, armazenamento e transporte da produção, até o 
tratamento específico que se deve dá aos resíduos sólidos oriundos dessa produção. Além disso, a forma como gerenciar esse tipo de negócio é um fator decisivo para esses agricultores.

As boas práticas agrícolas ou a prática de outra atividade como a apicultura, não conseguem ser implementadas sem antes, ocorrer uma mudança na forma de gerenciamento das pequenas propriedades rurais, quando essas não recorrem a procedimentos administrativos que facilitam e dão notoriedade aos seus produtos, ao mesmo tempo em que auxilia no aumento de produtividade, organização do tempo, negociação com clientes e fornecedores, etc. Desse modo, algumas das ações dos projetos de extensão ora expostos nesse estudo tentaram contribuir em duas realidades de pequenos produtores do sertão seridoense potiguar. A ideia inicial parte do pressuposto de que a formação acadêmica e profissional por meio da extensão promovida pelos Institutos Federais, proporcionam ao aluno e também a comunidade local, resultados muito interessantes de aprendizado, de troca de valores, de vivências que certamente contribuem significativamente para ambos os beneficiários.

Nesse sentido, com base nas ações do Projeto de Extensão "Realizando Boas Práticas Agrícolas com associados da agroindústria familiar do Povoado da Cruz/RN", a turma do 2 ㅇ período (2014.2) do Curso Superior de Tecnologia em Alimentos do IFRN/Campus Currais Novos, na disciplina Gestão Organizacional, desenvolveu atividades relacionadas às boas práticas agrícolas com foco no empreendedorismo, o que ocorreu de forma semelhante no ano seguinte (2015.2) em mais uma turma do mesmo curso, agora junto a Associação Cerrocoraense de Apicultores (Acapmel). Ambos os trabalhos seguiram a sugestão apresentada por Sediyama, Santos e Lima (2014, p. 836): "assim, cabe aos pesquisadores e técnicos, em parceria com os produtores, a viabilização de sistemas produtivos que garantam a qualidade desejada pelos consumidores e o retorno econômico desejado pelos agricultores". Além do mais, a ideia original dessas ações nas turmas se deu devido à convicção dos participantes dos projetos e da disciplina de que, por mais que se tratem os aspectos técnicos quanto às boas práticas agrícolas, se faz também necessário os pequenos agricultores e apicultores gerenciarem seus negócios.

De certo modo, tais ações extensionistas evidenciam uma das prioridades dos Institutos Federais que é estar alinhado aos processos locais, bem como a disponibilidade às comunidades desses processos locais aos conhecimentos produzidos pela instituição, como no caso da AgroCruz (agricultura) e da Acapmel (apicultura). Para Pacheco (2012), é nessa via que a extensão pode possibilitar a segmentos e setores que nem sempre são bem assistidos, como a zona rural, o acesso ao conhecimento científico e tecnológico a fim de criar condições favoráveis à inserção e permanência no trabalho, de geração de trabalho e renda e exercício da cidadania. Consequentemente, ao mesmo tempo em que a academia disponibiliza conhecimento para a comunidade local, esta transmite seus conhecimentos e vivências enriquecendo os currículos das áreas de ensino e pesquisa. Nessa troca de saberes e conhecimentos, "os Institutos Federais tornam-se espaço privilegiado para a democratização do conhecimento científico e tecnológico e valorização do conhecimento popular" (PACHECO, 2012, p. 52).

De acordo com Dolabela (1999), o contato, os depoimentos, a vivência com os empreendedores são imprescindíveis na formação e/ou enriquecimento da percepção do aluno sobre o perfil desses empreendedores. Nessa perspectiva, Cruz Júnior, Araújo, Wolf e Ribeiro 
(2006) explicam que a prática do empreendedorismo mostra-se cada vez mais frequente no Brasil como opção de carreira, frente às dificuldades socioeconômicas que assolam o país e reduzem as oportunidades para aqueles que querem ingressar no mercado de trabalho, corroborando as considerações de Souza (2012) em estudo sobre a introdução do tema empreendedorismo como componente curricular na educação brasileira, tema esse inserido permanentemente na grade curricular dos cursos técnicos e de tecnologia dos Institutos Federais.

Alguns estudos também evidenciam a necessidade de abordar o empreendedorismo em sala de aula, como Pereira (2001) que apresenta uma metodologia específica para desenvolver habilidades empreendedoras, especialmente com relação ao estudante universitário, ou como Bastos et al. (2006) que defende a inserção do empreendedorismo como matéria extracurricular e transdisciplinar a partir da escola básica, permitindo a incorporação ao ensino curricular obrigatório diversos conhecimentos que auxiliem e despertem nos alunos novos comportamentos empreendedores frente aos desafios específicos do mercado atual.

De fato, essa educação empreendedora que atinge principalmente o público estudantil jovem, tem-se solidificado como mecanismo de tentar despertar nesses alunos a importância sobre a inclusão no mercado de trabalho, seja como um profissional empregado com características distintas da grande maioria ou então como empreendedores que se tornam empregadores, tornando-se assim, um fator preponderante para promoção o desenvolvimento socioeconômico brasileiro (LIMA-FILHO, SPROESSER e MARTINS, 2009; BULGACOV, 2010), pois a educação empreendedora dissemina princípios que auxiliam no alcance de resultados em curto, médio e longo prazo, dependendo das circunstâncias e contextos em que se inserem os atores envolvidos nesse tipo de dinâmica, em especial, os jovens que possuem uma questão e desafio essencial, isto é, "saber o que fazer para aproveitar a nova onda de profissões do futuro" (MENDES e FILHO, 2012, p. 40).

De fato, além da capacitação técnica que é importante, se faz necessário um olhar mais atento para questões relacionadas ao mercado em si, ou seja, como orientar esses agricultores e apicultores quanto à comercialização dos seus produtos? De que forma auxiliá-los no gerenciamento do seu negócio? E os alunos enquanto futuros profissionais? Não seriam ações como essas que proporcionam a esses alunos a vivência da teoria na prática? São essas perguntas e tantas outras que caracterizam essas ações extensionistas imprescindíveis na formação humana e integral dos discentes, bem como na construção de projetos sustentáveis e promissores para toda a cadeia produtiva da região na qual essas instituições de ensino estão inseridas.

\section{METODOLOGIA}

Esse trabalho se caracteriza por uma pesquisa-ação (THIOLLENT, 1998) ou como bem enfatiza Stake (2011), uma pesquisa-ação participante, em que os alunos puderam literalmente 
adentrar na realidade do objeto de estudo e por meio de entrevistas, observações e conversas informais, extrair o máximo possível de informações para a realização do estudo. Por isso, a seguir se encontram algumas informações importantes sobre os fatos ocorridos durante os dois projetos em questão, a saber:

No período 2014.2 do IFRN/Campus Currais Novos, foi ofertada a disciplina Gestão Organizacional para a turma do 2 o período do Curso Superior de Tecnologia em Alimentos. Na oportunidade, o professor da disciplina tinha acabado de participar como voluntário do Projeto de Extensão "Realizando Boas Práticas Agrícolas com associados da agroindústria familiar do Povoado da Cruz/RN" do Edital 01/2014-PROEX/IFRN coordenado pelo Prof. Dr. Saint Clair Lira Santos. Foi então que surgiu a ideia de trabalhar os conteúdos teóricos da disciplina Gestão Organizacional na realidade do projeto de extensão, ou seja, a partir da teoria, os alunos dariam suas contribuições na prática do projeto.

No ano seguinte, especificamente no semestre 2015.2, mais uma turma do 20 período do Curso Superior de Tecnologia em Alimentos cursava a disciplina Gestão Organizacional. Considerando os resultados favoráveis das ações do ano anterior, optamos por uma dinâmica pedagógica semelhante, entretanto, não mais com os agricultores do Povoado da Cruz, mas junto a Associação Cerrocoraense de Apicultores, a Acapmel. Nesse sentido, foram dois projetos distintos em turmas diferentes, mas com a mesma dinâmica pedagógica envolvendo a inserção do aluno nas práticas e vivências dessas comunidades.

Dessa forma, os alunos puderam compreender os desafios dos agricultores que tentam desenvolver uma produção com base nas boas práticas agrícolas, bem como as dificuldades enfrentadas pelos apicultores na região, principalmente devido à estiagem prolongada. Nos casos apresentados, os objetos de estudo foram a propriedade rural do Sr. César Salustiano no Povoado da Cruz, na zona rural do município de Currais Novos/RN e a Associação Cerrocoraense de Apicultores (Acapmel).

Em relação ao Sr. César Salustino, este agricultor recebeu a turma para expor seu trabalho e principalmente para apresentar a mudança que ocorrera em sua dinâmica de trabalho após as intervenções do Prof. Saint Clair com o projeto de extensão que enfatizava as boas práticas agrícolas. De fato, esse contato da turma com um agricultor simples e humilde, mas que tem visão de futuro e determinação, se tornou o momento ímpar no desenvolvimento desse trabalho. A partir de então, o professor da disciplina utilizou a realidade do Sr. César Salustiano para trabalhar todos os conteúdos da disciplina, tais como: planejamento, estratégia, gestão financeira, marketing, etc.

Em seguida, foi repassada a turma de alunos a ideia do trabalho final da disciplina que envolveu a temática empreendedorismo e gestão aliada às boas práticas agrícolas, tendo como base o caso do Sr. César no Povoado Cruz. O trabalho final da disciplina foi precedido por diversas atividades em grupos (visitas, pesquisas bibliográficas, entrevistas), sempre orientadas pelo professor. Esses grupos foram divididos de acordo com os setores comumente encontrados nas empresas, a saber: setor financeiro, de marketing, de produção e de recursos humanos. Um grupo ficou responsável para liderar os demais grupos, por meio de acompanhamento do 
cronograma de atividades, além de providenciar os detalhes para o evento em que foi apresentado o resultado final da disciplina, ou seja, a culminância de todo o trabalho desenvolvido na disciplina.

Os grupos assim divididos aprofundaram os conhecimentos teóricos em sala de aula e através de pesquisas, e concomitantemente, aplicaram esses conhecimentos na prática, isto é, no caso do Sr. César Salustiano. As visitas à propriedade rural, as entrevistas feitas ao agricultor, dentre outras ações, permitiram que os alunos tivessem uma experiência mais real dos desafios e oportunidades do negócio em questão.

Por fim, ocorreu um evento em que as atividades dos grupos foram apresentadas para toda a turma, para os agricultores (Sr. César e seu irmão, que é seu sócio no negócio), além da comunidade do Povoado da Cruz que porventura quis participar. O evento ocorreu na própria comunidade, no prédio da associação de produtores da localidade. Essa foi mais uma característica diferenciada desse trabalho, pois possibilitou a "saída" (em relação aos "muros" da instituição) desses estudantes que tiveram a oportunidade de ter contato com outros ambientes e com pessoas comuns que possuem seus negócios com suas próprias expectativas.

As apresentações foram feitas de acordo com cada grupo (setores da empresa) que apresentou detalhadamente suas análises e sugestões de melhorias para o negócio em questão. Todavia, todos os alunos, independente do grupo, tinham em mente a visão holística do negócio, ou seja, todos "criaram" uma empresa - que fora denominada AgroCruz - tendo por base todas as características observadas na propriedade do Sr. César Salustiano, além das oportunidades por eles visualizadas, bem como das diversas sugestões de melhorias que foram apresentadas, tais como a criação de uma logomarca, estratégias de vendas, um adequado planejamento financeiro, etc.

No que tange à Associação Cerrocoraense de Apicultores (Acapmel), o Sr. José Luiz, presidente e associado da Acapmel, foi o principal articulador das visitas e exposições sobre o trabalho da referida associação. O apicultor fez explanações excelentes sobre o mundo da apicultura, desde o cultivo das abelhas até o processamento do mel. Foram feitas visitas em sua propriedade rural para conhecer as colméias e também a sede da Acapmel, localizada na zona rural do município de Cerro Corá/RN.

De forma semelhante ao que fora proposto e desenvolvido no ano anterior com o Sr. César Salustiano (AgroCruz), após a visita e feito um diagnóstico das principais necessidades da Acapmel, os alunos foram divididos em grupos e passaram a desenvolver todo um planejamento referente aquele negócio. Um detalhe interessante se deu com o grupo responsável pelo setor de Pesquisas da Acapmel, composto por dois alunos que já eram técnicos em alimentos (alunos egressos do curso técnico de nível médio integrado e agora estudantes do curso superior de tecnologia em alimentos) e que puderam dá uma colaboração mais efetiva sobre a qualidade do mel processado pela referida associação, fazendo exames laboratoriais que revelaram dados importantes. Esse foi um dos pontos apresentados na culminância do trabalho ao término da disciplina. 
Realizadas as ações em grupo e as constantes discussões em sala de aula e in loco, o Sr. José Luiz ajudou toda a turma na articulação para a apresentação final do trabalho, que ocorreu no Centro Pastoral da Paróquia de São Francisco no município de Lagoa Nova/RN, com a participação de um número significativo de associados da Acapmel e de algumas autoridades políticas, como o prefeito de Lagoa Nova naquela ocasião, o Sr. João Maria. Vale a pena lembrar que apesar da localização da sede da associação ser na zona rural de Cerro Corá, seus associados estão espalhados em outros municípios do Seridó potiguar, como Lagoa Nova e Currais Novos.

\section{RESULTADOS E DISCUSSÕES}

Nesse tópico, algumas figuras são apresentadas, evidenciando os resultados de toda uma experiência muito significativa com os alunos do curso superior de Tecnologia em Alimentos, que aliaram teoria e prática, possibilitando uma visão mais dinâmica do mercado de trabalho e especialmente em questões relacionadas ao empreendedorismo com base nas boas práticas agrícolas e na atividade da apicultura. Hengemühle (2014) evidencia que, no Brasil, ainda há uma distância substancial entre o idealizado e o necessário em relação às práticas pedagógicas desenvolvidas no atual ensino. Entretanto, o autor afirma que o ensino do empreendedorismo com base numa educação empreendedora é uma das vertentes a serem utilizadas como propulsor de mudanças. É nessa perspectiva de educação empreendedora aliada a prática extensionista, que trabalhos como estes podem ser diferenciais na vida estudantil e profissionais dos discentes, sem falar dos benefícios que chegam as comunidades locais.

Em regiões com baixa dinâmica econômica e dificuldades enfrentadas por questões climáticas, como é o caso do sertão no Seridó potiguar, todas as ajudas são muito bem-vindas. No decorrer de todas as ações desenvolvidas nos referidos projetos de extensão, é perceptível a alegria e satisfação dos agricultores e apicultores em ter uma instituição de ensino de qualidade por perto. Depoimentos dados nas visitas técnicas, nas palestras, nos testemunhos de vida, confirmam esse sentimento de gratidão dessas pessoas com aquilo que é uma das finalidades da educação profissional e tecnológica por meio dos Institutos Federais, ou seja, interagir verdadeiramente com a sociedade, seja através de ações culturais ou transferência de tecnologias. O IFRN (2012, p. 202) dá uma ênfase substancial nesse quesito da extensão enquanto promotora de mudanças e melhorias para as comunidades ao afirmar: com a sociedade, viabilizando-se propostas que promovam ações transformadoras da realidade social. Busca-se também articular a extensão ao ensino e à pesquisa, na tentativa de criar mecanismos que inter-relacionem o fazer acadêmico aos saberes produzidos em outros contextos sociais, em respeito à tradição, ao saber e à cultura populares (...). Somente assim, o IFRN, de forma mais incisiva, pode alcançar a 
comunidade e estabelecer relações próximas com ela, a fim de cumprir com o papel e a responsabilidade social da Instituição.

Abaixo seguem algumas figuras que ilustram muito bem as ações desenvolvidas nos projetos, a começar do contato com o agricultor Sr. César Salustiano, que na sua simplicidade e timidez, deu "aulas" de boas práticas agrícolas para todos os presentes. Ademais, o mesmo agricultor é exemplo de mudança de postura em relação ao tratamento e cultivo da terra, após orientações do Prof. Saint Clair com o projeto "Boas Práticas Agrícolas". Atualmente, sua propriedade é visitada constantemente por alunos dos Institutos Federais, dentre eles os alunos do curso de Agroecologia do Campus Ipanguaçu, universitários do curso de Agronomia da Universidade Federal Rural do Semi-Árido (UFERSA) de Mossoró além de estudantes da rede pública de ensino. Os resultados do projeto foram tão animadores do ponto de vista do aumento da produção, da diversificação dos plantios, dentre outros, que diversas reportagens foram feitas na mídia local sobre o caso, dentre estas, uma reportagem veiculada para todo o estado do Rio Grande do Norte, apresentando as boas práticas agrícolas utilizadas pelo Sr. César Salustiano, como um exemplo de empreendedorismo e sucesso.

Na Figura 1 o agricultor apresenta e explica como fazer e quais os benefícios do composto orgânico para sua propriedade. Nesse quesito, os alunos que se agruparam para analisar os aspectos financeiros da "AgroCruz" identificaram uma redução drástica dos insumos anteriormente adquiridos pelo agricultor, em sua maioria, agrotóxicos, que elevavam consideravelmente seus custos operacionais. Na oportunidade, o composto orgânico e a formação de um biofertilizante, já seguindo as orientações das boas práticas agrícolas, tem proporcionado não apenas a redução dos custos, mas um incremento nos lucros obtidos, permitindo até mesmo um retorno para investimentos, sugestões que foram levantadas pelos alunos e repassadas ao agricultor.

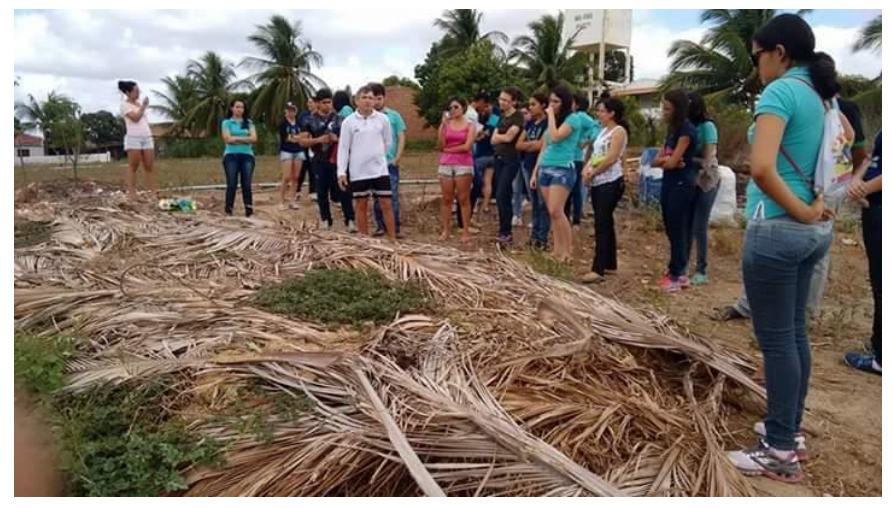

Figura 1 - Boas práticas agrícolas: composto orgânico

Fonte: Arquivo pessoal do autor

O ponto alto desses projetos é a convivência com esses profissionais, ou melhor, com essas pessoas, gente da gente, que com muito esforço desenvolvem seus trabalhos em busca de dias melhores. Numa dessas ocasiões, como revela a Figura 2, o Sr. César Salustiano falou um 
pouco de sua vida antes e depois do Projeto de Extensão "Boas Práticas Agrícolas", emocionando todos os presentes. São depoimentos como esse que revelam de forma muito nítida o benefício da presença do Instituto Federal junto a comunidade. É uma espécie de "oásis no sertão".

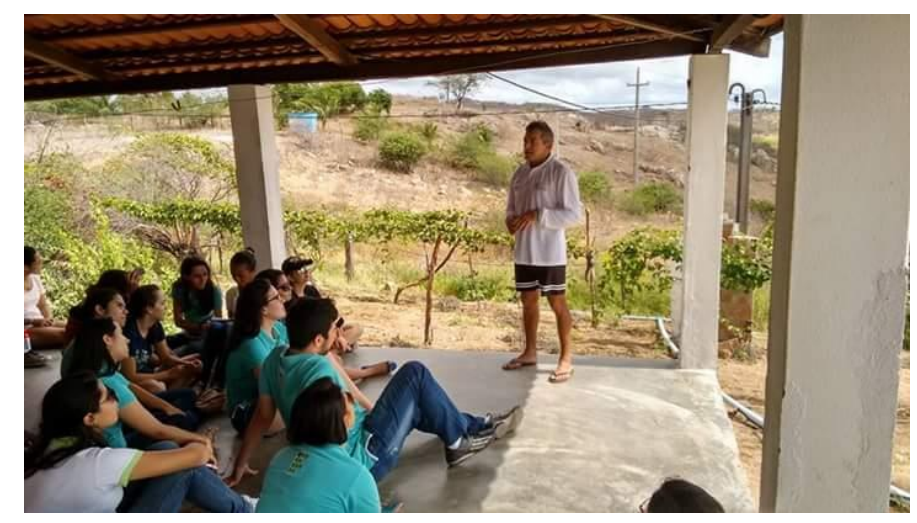

Figura 2 - Relato de uma vida antes e depois das Boas Práticas Agrícolas

Fonte: Arquivo pessoal do autor

Dentre várias ações desenvolvidas pelos alunos, a Figura 3 demonstra a Logomarca da AgroCruz que foi desenvolvida especialmente para o projeto. O slogan (Saúde à sua mesa!), as personagens da logomarca (verduras e hortaliças como enfermeiros, ou seja, previnem doenças e auxiliem na saúde) e o próprio nome da empresa (AgroCruz) foram ideias dos alunos que foram recebidas com muita alegria pelo agricultor. Atualmente, o Sr. César dispõe de uma banca numa feira de produtos orgânicos e a marca "AgroCruz" continua sendo utilizada, demonstrando que a sugestão dos alunos não foi apenas acolhida, mas literalmente posta em prática, possibilitando a criação de uma identificação específica e uma marca própria para os produtos produzidos na propriedade do agricultor.

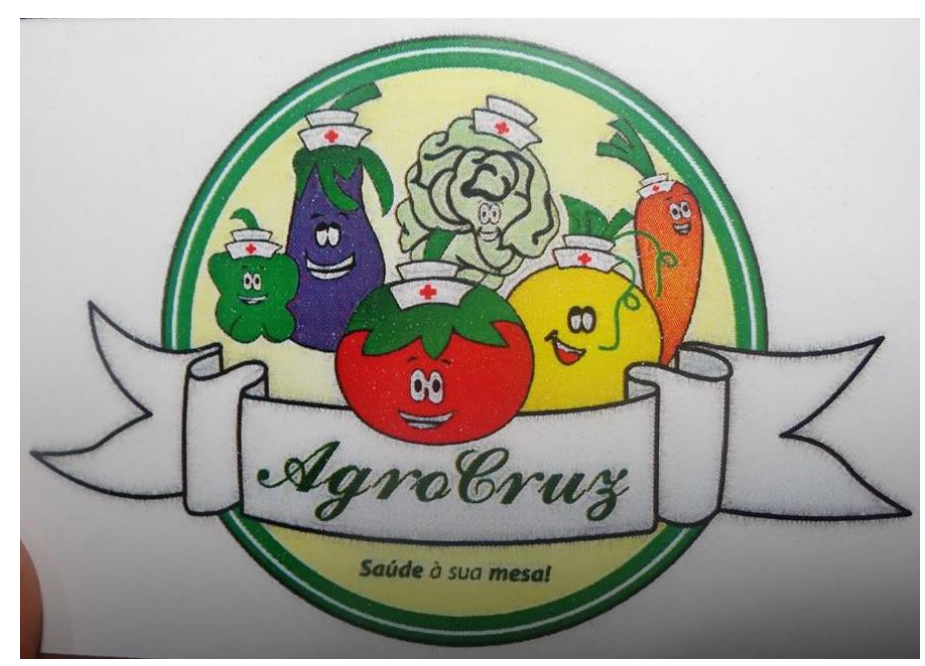

Figura 3 - Logomarca da AgroCruz desenvolvida pelos alunos

Fonte: Arquivo pessoal do autor 
A culminância do trabalho (Figura 4) se deu numa noite de apresentações realizada na própria comunidade rural, mais especificamente na sede da Miniagroindústria de polpa de frutas do Povoado Cruz, na zona rural do município de Currais Novos. Os grupos que se dividiram nas áreas da empresa (finanças, marketing, recursos humanos, etc.) fizeram suas exposições que foram repassadas primeiramente para o agricultor César e os demais presentes.

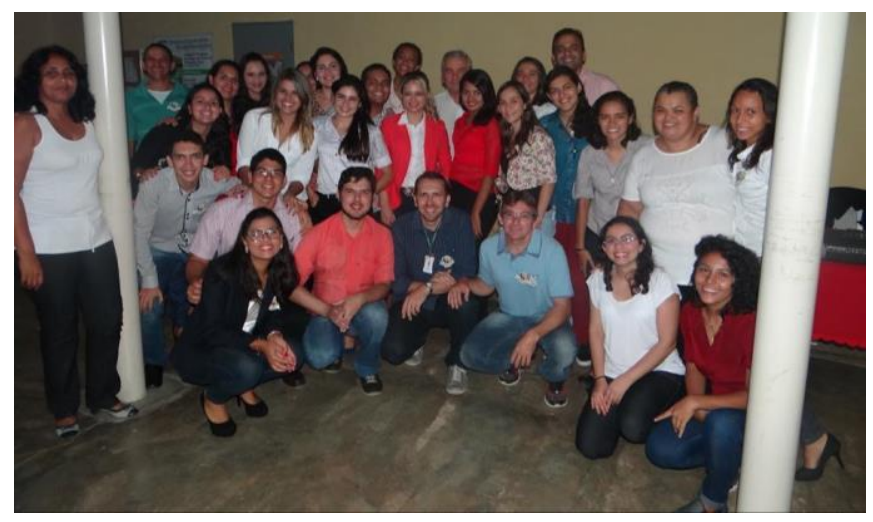

Figura 4 - Participantes do trabalho no encerramento da disciplina

Fonte: Arquivo pessoal do autor

Semelhantemente ao que ocorreu com a primeira turma do Curso Superior de Tecnologia em Alimentos junto ao agricultor César Salustiano, ou seja, a empatia e alegria em conviver com esses homens valentes sertanejos, também aconteceu junto aos associados da Associação Cerrocoraense de Apicultores (Acapmel), especialmente na figura do Sr. José Luiz. As Figuras 5 e 6 mostram o dia em que os estudantes no período 2015.2 visitaram a sede da Associação, conhecendo todas as etapas do processamento do mel e tendo literalmente uma aula sobre o "mundo das abelhas". Na oportunidade, os alunos puderam fazer um diagnóstico das necessidades e desafios dos apicultores quanto ao seu negócio, para a partir de então, traçarem um planejamento de ações que foram apresentadas ao término da disciplina, conforme veremos mais na frente.

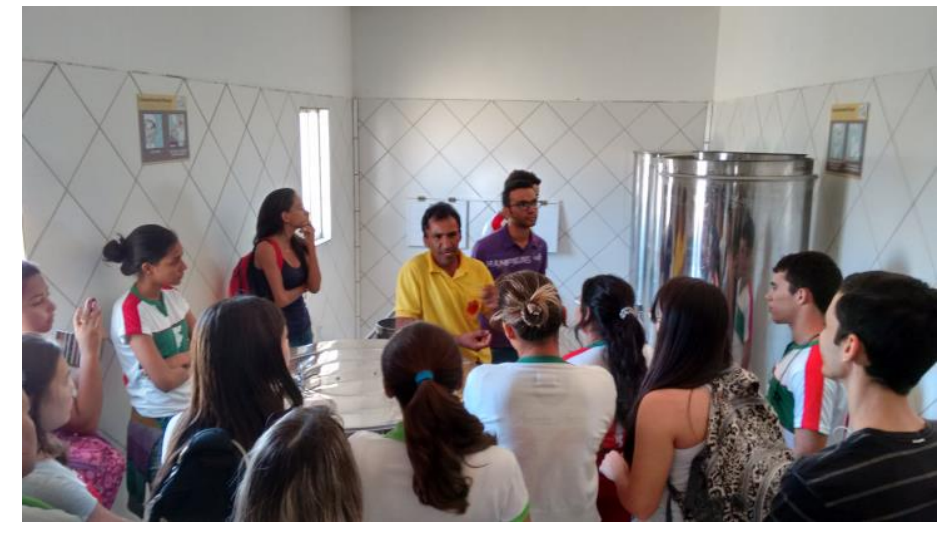

Figura 5 - Visita técnica a sede da Associação Cerrocoraense de Apicultores (Acapmel): processamento do mel Fonte: Arquivo pessoal do autor 


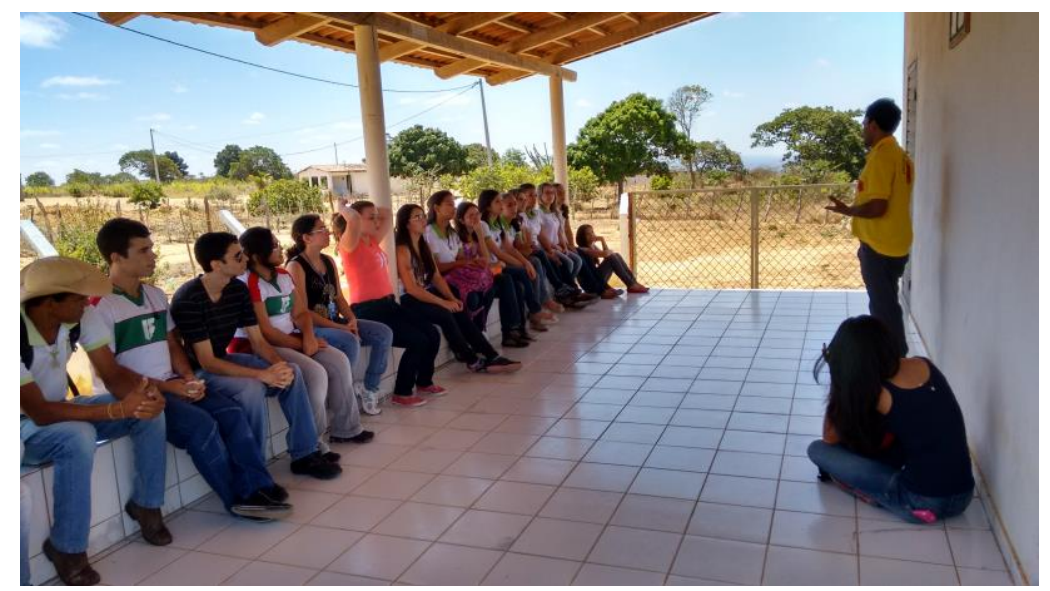

Figura 6 - Visita técnica a sede da Associação Cerrocoraense de Apicultores (Acapmel): o mundo das abelhas

Fonte: Arquivo pessoal do autor

A Figura 7 apresenta um momento importante na apresentação final do trabalho da disciplina que fora desenvolvida unindo literalmente o ensino, a pesquisa e a extensão. Na figura em destaque se encontra um apicultor e associado da Acapmel que faz um depoimento de agradecimento a toda a turma pelo trabalho apresentando, evidenciando inclusive as dificuldades enfrentadas pelos apicultores em longos períodos de estiagem, o que gera uma desmotivação e grande preocupação para essa atividade econômica. A fala do associado era numa perspectiva de esperança e "rejuvenescimento" para os apicultores da região quando apresentadas as diversas sugestões dadas pelos alunos. Esse certamente foi um dos momentos muito felizes do projeto, confirmando ainda mais a importância da extensão, isto é, a interação do Instituto Federal com a sociedade.

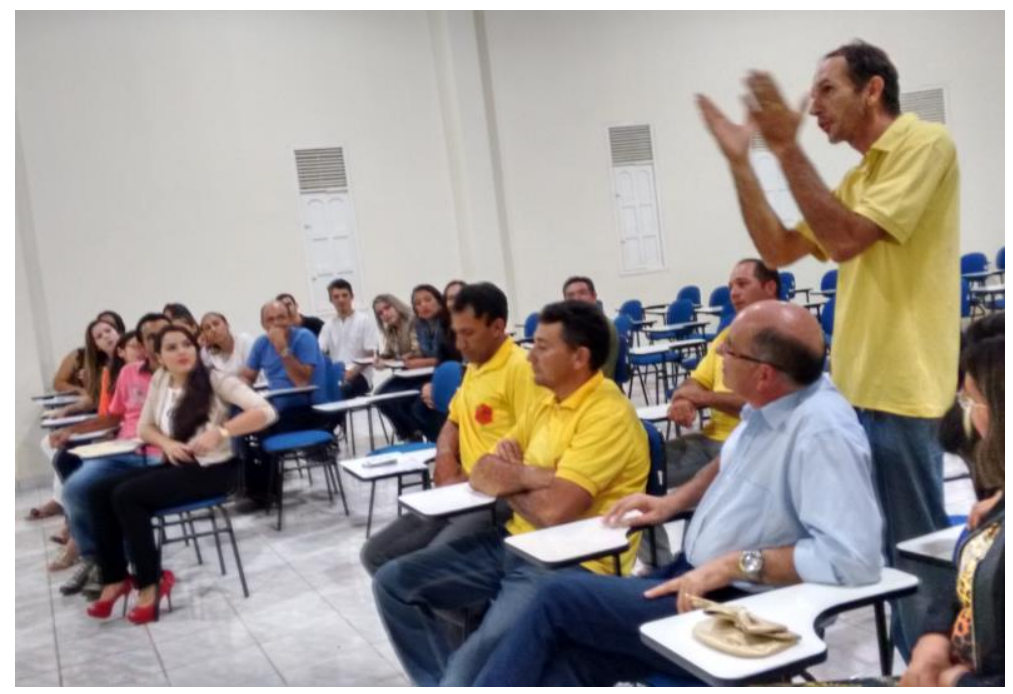

Figura 7 - Depoimento de um apicultor e associado no encerramento das atividades da disciplina

Fonte: Arquivo pessoal do autor 
Por fim, a Figura 8 apresenta os alunos da turma, o professor, os associados da Acapmel e algumas autoridades políticas que estiveram presentes no evento que culminou com 0 encerramento das atividades do projeto e da disciplina.

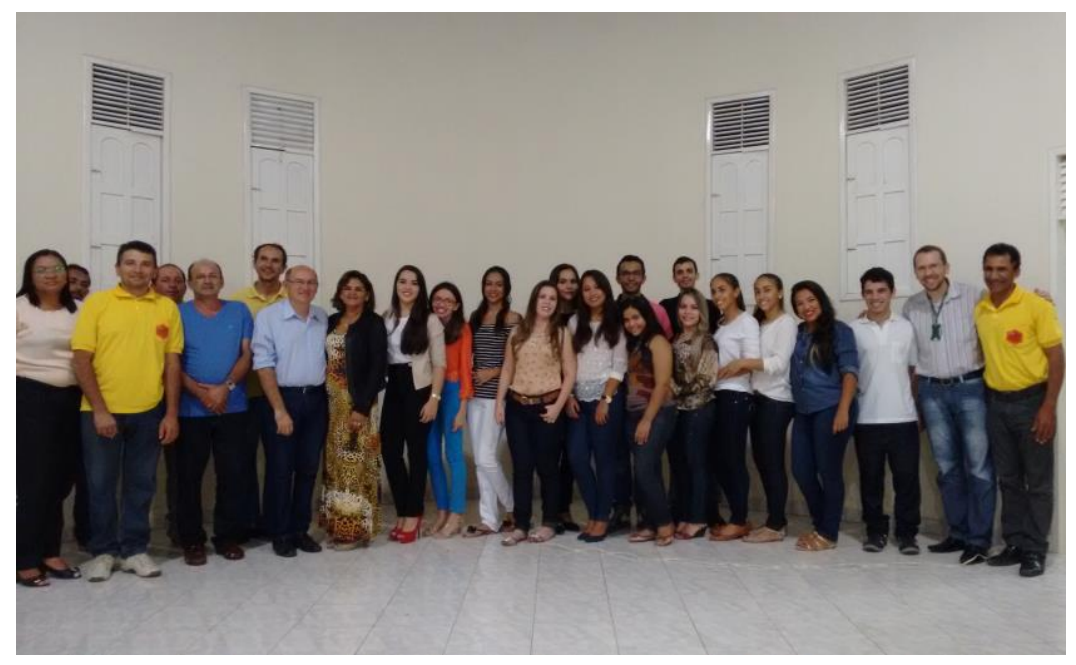

Figura 8 - Participantes do trabalho no encerramento da disciplina

Fonte: Arquivo pessoal do autor

Dolabela (1999) aponta razões plausíveis para que a cultura empreendedora seja disseminada principalmente nas instituições de ensino, pois esta estimula a autorrealização e o desenvolvimento, incidindo no desenvolvimento local, apoiando a pequena empresa, ampliando a base tecnológica, respondendo ao desemprego, apontando armadilhas a serem evitadas, bem como auxiliando numa reorientação do ensino brasileiro. Esse pensamento do autor pode ser muito bem traduzido por tudo aquilo que foi proposto nesses dois projetos, confirmando a necessidade da existência permanente do tripé institucional - ensino, pesquisa e extensão - para que os objetivos da educação profissional e tecnológica ocorram satisfatoriamente.

\section{CONCLUSÃO}

A disseminação do conhecimento tem tomado proporções cada vez mais difusas, haja vista a facilidade de acesso às fontes de informação de forma geral. Entretanto, o modo como esse conhecimento tem sido aplicado ou até mesmo compreendido pelas pessoas é um fator preocupante, pois a cultura imediatista da atualidade já imergiu também na educação. Esse detalhe se torna importante de ser observado porque a formação de um profissional perpassa por várias etapas, dentre elas, a formação humana e integral, que requer o contato com exemplos e/ou referências nos mais diversos setores da sociedade.

Nesse contexto, as ações e práticas extensionistas desenvolvidas nesses projetos que foram apresentadas nesse estudo envolvem o público estudantil jovem, na tentativa de Vol. 1 (2018) 
despertar nesses alunos a importância sobre os desafios para a inserção no mercado de trabalho, seja como um profissional empregado com características distintas da grande maioria, ou então como empreendedores que se tornam empregadores. Além disso, os benefícios gerados para as comunidades atendidas, nos casos da AgroCruz e da Acapmel, e a troca de experiências com eles, são imensuráveis.

Considerando a importância da extensão enquanto política educacional defendida por Pacheco $(2011,2015)$ e IFRN (2012), que atende as determinações da Lei 11.892/2008, incluindo nesta o apoio e estímulo ao empreendedorismo, percebe-se a necessidade de implementar em "sala de aula" aquilo que Dolabela (1999) chama de Oficina do Empreendedor, deixando muito claro a necessidade de disseminar a cultura empreendedora, especialmente quando se almeja o desenvolvimento local por meio dos pequenos produtores e empresas. Além do mais, trabalhos como estes possibilitam uma aproximação maior entre a comunidade e as instituições de ensino, aqui representada pelo Instituto Federal de Educação, Ciência e Tecnologia do Rio Grande do Norte - Campus Currais Novos, cumprindo dessa forma com um dos principais objetivos dessas instituições, isto é, promover o desenvolvimento local das regiões em que estas se encontram.

Sendo assim, sugere-se que trabalhos semelhantes que já foram realizados ou que através desses exemplos expostos possam vir a ser desenvolvidos, sejam apresentados seus resultados, suas experiências possam ser socializadas, independente das temáticas, segmentos econômicos ou sociais e realidades ou contextos geográficos estudados. Certamente, experiências como essas enriquecem e beneficiam toda a comunidade estudantil interna e externa.

\section{REFERÊNCIAS}

1. BASTOS, A. T. et al. Empreendedorismo e educação: o caso do Projeto Empreendedorismo na Escola, 2006. Disponível em: <http://www.sebrae.com.br>. Acesso em 20/11/2015.

2. BASTOS, M. S. R. Ferramentas da ciência e tecnologia para a segurança dos alimentos. EMBRAPA: Fortaleza, 2008.

3. BULGACOV, Y. M., et. al. Jovem empreendedor no Brasil: a busca do espaço da realização ou a fuga da exclusão? Revista de Administração Pública, v. 45, n. 3, 2010.

4. BRASIL. Lei 11.892, de 29 de dezembro de 2008. Institui a Rede Federal de Educação Profissional, Científica e Tecnológica, cria os Institutos Federais de Educação, Ciência e Tecnologia e dá outras providências. Diário oficial [da] União, Poder executivo, Brasília, DF, Ano CXLV, n. 253, 30 de dez. 2008. Seção 1, p. 1-3. Disponível em: < http://www.planalto.gov.br/ccivil_03/_ato2007-2010/2008/lei/l11892.htm>. Acesso em: 05 jan. 2018.

5. BRASIL, Ministério da Educação. Expansão da Rede Federal. 2016. Brasília: Ministério da Educação. Disponível em: <http://redefederal.mec.gov.br/expansao-da-rede-federal>. Acesso em: 06 Dez. 2017. 
6. Políticas públicas para a educação profissional e tecnológica. 2004. Brasília: Ministério da Educação, Ciência e Tecnologia. Disponível em: <http://portal.mec.gov.br/setec/arquivos/pdf/pp.pdf>. Acesso em: 06 Dez. 2017.

7. CODEX ALIMENTARIUS COMMISSION. Proposed draft code of hygienic practice for pre-cut fruits and vegetables (at step 3): committee on food hygiene, thirty-third session. Washington, DC, 2000.

8. CRUZ JÚNIOR, J. B.; ARAÚJO, P. C.; WOLF, S. M.; RIBEIRO, T. V. A. Empreendedorismo e educação empreendedora: confrontação entre a teoria e prática. Revista de Ciências da Administração, v. 8. n. 15, jan/jun. 2006.

9. DOLABELA, F. Oficina do Empreendedor: A metodologia de ensino que ajuda a transformar conhecimento em riqueza. São Paulo: Cultura Editores Associados, 1999.

10. FREIRE, P. Extensão ou comunicação? 17. ed. São Paulo: Paz e Terra, 2015.

11. HENGEMÜHLE, A. Desafios educacionais na formação de empreendedores. Porto Alegre: Penso, 2014.

12. INSTITUTO FEDERAL DE EDUCAÇÃO, CIÊNCIA E TECNOLOGIA DO RIO GRANDE DO NORTE. Projeto Político-Pedagógico do IFRN: uma construção coletiva - documento-base. Natal: IFRN Ed., 2012.

13. _. IFRN. Institucional: função social e principais objetivos. Natal. Disponível em: <http://portal.ifrn.edu.br/institucional/default-page>. Acesso em: 05 Dez. 2017.

14. LIMA-FILHO, D. O.; SPROESSER, R. L.; MARTINS, E. L. C. Empreendedorismo e Jovens Empreendedores. Revista de Ciências da Administração, v. 11, n. 24, maio/ago. 2009.

15. MANUAL "Boas Práticas Agrícolas para a Agricultura Familiar". Disponível em: http://rlc.fao.org/es/agricultura/bpa. Acesso em 20.11. 2015.

16. MENDES, J.; FILHO, I. Z. Empreendedorismo para Jovens: ferramentas, exemplos reais e exercícios para alinhar a sua vocação com o seu projeto de vida. São Paulo: Atlas, 2012.

17. NEVES, M. C. P. Conhecendo as Boas Práticas Agrícolas para a produção de alimentos seguros. Comunicado Técnico n. 94 - EMBRAPA, Jan./2007.

18. PACHECO, E. (Org.). Institutos Federais: uma revolução na educação profissional e tecnológica. São Paulo: Moderna, 2011.

19. Fundamentos político-pedagógicos dos institutos federais: diretrizes para uma educação profissional e tecnológica transformadora. Natal: IFRN, 2015.

20. PENTEADO, S. R. Cultivo ecológico de Hortaliças: como cultivar hortaliças sem veneno. Ed. Grafimagem: Campinas, 2007.

21. PEREIRA, S. M. A formação do empreendedor. 191f. Tese (Doutorado em Engenharia de Produção) - Departamento de Engenharia de Produção e Sistemas, Universidade Federal de Santa Catarina, Florianópolis, 2001.

22. SEDIYAMA, M. A. N.; SANTOS, I. C.; LIMA, P. C. Cultivo de hortaliças no sistema orgânico. Revista Ceres, v. 61. Viçosa. nov./dez. 2014.

23. SOUZA, S. A. A introdução do empreendedorismo na educação brasileira: primeiras 
considerações. Revista Educação \& Linguagem, v. 15, n. 26, jul./dez. 2012.

24. STAKE, R. E. Pesquisa Qualitativa: estudando como as coisas funcionam. Porto Alegre: Penso, 2011.

25. THIOLLENT, M. Metodologia da pesquisa-ação. 8. ed. São Paulo: Cortez, 1998. 